\title{
Universiteit
}

Leiden

The Netherlands

\section{The role of childhood abuse in HPA-axis reactivity in Social Anxiety} Disorder: A pilot study

Elzinga, B.M.; Spinhoven, P.; Berretty, E.W.; Jong, P. de; Roelofs, K.

\section{Citation}

Elzinga, B. M., Spinhoven, P., Berretty, E. W., Jong, P. de, \& Roelofs, K. (2010). The role of childhood abuse in HPA-axis reactivity in Social Anxiety Disorder: A pilot study. Biological Psychology, 83, 1-6. Retrieved from https://hdl.handle.net/1887/15128

Version: $\quad$ Not Applicable (or Unknown)

License: $\quad$ Leiden University Non-exclusive license

Downloaded from: https://hdl.handle.net/1887/15128

Note: To cite this publication please use the final published version (if applicable). 


\title{
The role of childhood abuse in HPA-axis reactivity in Social Anxiety Disorder: A pilot study
}

\author{
Bernet M. Elzinga ${ }^{\text {a,*}}$, Philip Spinhoven ${ }^{\text {a,b }}$, Ed Berretty ${ }^{c}$, Paula de Jong ${ }^{\text {d }}$, Karin Roelofs ${ }^{a}$ \\ ${ }^{a}$ Leiden University Institute for Psychological Research, Clinical Psychology Unit, The Netherlands \\ ${ }^{\mathrm{b}}$ Department of Psychiatry LUMC, The Netherlands \\ ${ }^{c}$ Outpatient Clinic for Anxiety Disorders PsyQ The Netherlands \\ ${ }^{\mathrm{d}}$ Outpatient Clinic for Psychotrauma PsyQ The Netherlands
}

\section{A R T I C L E I N F O}

\section{Article history:}

Received 16 June 2009

Accepted 10 September 2009

Available online 16 September 2009

\section{Keywords:}

Cortisol

HPA-axis

Stress

Childhood abuse

Social Phobia

Post-traumatic Stress Disorder

\begin{abstract}
A B S T R A C T
Background: Studies on depression have found that childhood abuse (CA) is associated with a persistent sensitization of the hypothalamic-pituitary-adrenal (HPA)-axis to stress in adulthood. So far, it is unknown whether this HPA-axis sensitization is specific to depression, or whether this is a more general outcome associated with CA in patients with mood and anxiety disorders. The aim of this study was to investigate whether CA is associated with enhanced cortisol reactivity to psychosocial stress in Social Anxiety Disorder (SAD).

Methods: Salivary cortisol levels before, during, and after exposure to psychosocial stress (i.e., Trier Social Stress Task, TSST) in SAD patients with a history of childhood abuse (SAD + CA, $n=9)$ were compared to cortisol levels in SAD patients without a history of childhood abuse (SAD - CA, $n=9$ ), patients with PTSD related to childhood abuse $(n=16)$, and healthy controls without a history of childhood abuse $(n=16)$.

Results: Analyses showed that the SAD + CA group had a strongly increased cortisol reactivity (mean peak: $17.5 \pm 1.9 \mathrm{nmol} / \mathrm{l}$ ) compared to $\mathrm{SAD}-\mathrm{CA}$ (mean peak: $9.0 \pm 1.1 \mathrm{nmol} / \mathrm{l}$ ), PTSD (mean peak: $9.0 \pm 1.1 \mathrm{nmol} / \mathrm{l}$ ) and healthy controls (mean peak: $9.6 \pm 1.4 \mathrm{nmol} / \mathrm{l}$ ), whereas baseline cortisol levels did not differ. The enhanced increase in the SAD + CA group was not explained by stronger anxiety in response to the TSST.

Conclusions: Consistent with the findings in depression, these results show for the first time that childhood abuse is also associated with strongly increased cortisol reactivity in SAD. When replicated in a larger sample, these findings may have important implications for the treatment of SAD.
\end{abstract}

(c) 2009 Elsevier B.V. All rights reserved.

\section{Introduction}

Social Anxiety Disorder (SAD) is the most common anxiety disorder, which is characterized by persistent fear and avoidance of social situations (Stein and Stein, 2008; Mannuzza et al., 1995). The causes and pathogenesis of SAD are not well elucidated. Besides inheritable traits, several studies reported that childhood abuse (CA), and particular emotional abuse, is an important risk factor for the development of SAD (Gibb et al., 2007; Heim and Nemeroff, 2001).

Research in animals found that chronic exposure to early adverse events, such as maternal deprivation, may have a lasting impact on the neurobiology of the stress response, particularly on

\footnotetext{
* Corresponding author at: P.O. Box 9555, 2300 RB Leiden, The Netherlands.

Tel.: +31 71 5273745; fax: +31 715274678 .

E-mail address: Elzinga@fsw.leidenuniv.nl (B.M. Elzinga).
}

the stress-regulating hypothalamic-pituitary-adrenal (HPA) axis (see Heim and Nemeroff, 2001; Kaufman et al., 2000; Sanchez, 2006, for reviews). Epigenetic regulation of hippocampal glucocorticoid receptor expression may mediate the effects of early life experiences on adult behavior (Weaver et al., 2004, 2007; McGowan et al., 2009). Despite the importance for our understanding of how childhood abuse might lead to psychopathology, only a few studies investigated the impact of early adverse experiences on HPA reactivity (Heim et al., 2000; Bremner et al., 2003; Elzinga et al., 2003). Consistent with the animal studies, these studies found that CA is associated with increased HPA-axis sensitivity to stress in women with MDD (Heim et al., 2000), and to a smaller extent in Post-traumatic Stress Disorder (PTSD) (Bremner et al., 2003; Elzinga et al., 2003). In healthy subjects, in contrast, CA has been related to hypo-responsiveness of the HPA-axis to psychosocial stress (Elzinga et al., 2008; Carpenter et al., 2007). An important question that needs to be elucidated is whether HPAaxis sensitization is specific for MDD (and PTSD), or whether it is a 
more general outcome of CA in patients with mood or anxiety disorders, including patients with SAD.

So far, a number of studies investigated cortisol reactivity to psychosocial stress in SAD, with mixed results (Condren et al., 2002; Furlan et al., 2001; Levin et al., 1993; Martel et al., 1999). Recently, we reported increased cortisol responses to the Trier Social Stress Test (TSST) in SAD compared to PTSD and healthy controls (Roelofs et al., 2009). This was in line with one other study reporting increased cortisol responses to psychological stress in SAD (Condren et al., 2002), but other investigations failed to find group differences (Furlan et al., 2001; Levin et al., 1993; Martel et al., 1999). Besides several methodological differences, CA might play an important role in these (inconsistent) findings, as none of these studies included information about the presence of CA.

The aim of the present retrospective study is to investigate HPA reactivity to a psychosocial stressor (TSST) in patients with SAD who report a history of (emotional, physical, or sexual) CA vs patients with SAD who do not report experiences of abuse during childhood. To investigate the specificity of the relation between abuse and HPA reactivity in SAD, we also included patients with PTSD related to CA and healthy participants without a history of CA.

\section{Methods}

\subsection{Participants}

Demographic variables and other characteristics of the groups are presented in Table 1. Participants described here were part of a larger study (see Roelofs et al., 2009). Patients with generalized SAD and PTSD were diagnosed with the Structured Clinical Interview for DSM-IV Axis-I Disorders, SCID-i/p (First et al., 1996). Healthy control (HC) participants were recruited via advertisements in local newspapers.
Exclusion criteria were: age $<18$ or $>65$ years, left handedness, psychotic disorder, use of neuroleptics, substance use/addiction, chronic disease, use of corticosteroids max 6 months before participation, and pregnancy or breast feeding.

The SAD group with a history of childhood abuse (SAD + CA) consisted of SAD patients who reported emotional, physical or sexual abuse involving the primary caretaker, which took place before the age of 16 (as assessed with the TEC). Similarly, for the PTSD group, participants were only included when posttraumatic stress symptoms were related to adverse events experienced before the age of 16 (excluding $n=3$ patients from our original sample with PTSD associated with trauma that occurred after age 16). From the HCs, participants who reported emotional, physical or sexual abuse that had taken place before the age of 16 (excluding $n=6$ healthy controls from the original sample) were excluded. These inclusion and exclusion criteria resulted in the following groups: $\mathrm{SAD}+\mathrm{CA}, n=9$; SAD - CA, $n=9$; PTSD, $n=16$; HC, $n=16$.

All participants were instructed to minimize physical exercise during the hour preceding the experiment and not to take large meals, coffee, drinks with low $\mathrm{pH}$ or cigarettes, because these variables can affect cortisol levels. The study was approved by the local ethics committee and all participants provided written informed consent.

\subsection{Materials}

\subsubsection{The Trier Social Stress Test}

The psychological challenge test consisted of a free speech ( $5 \mathrm{~min}$ ) and a mental arithmetic task ( $5 \mathrm{~min}$ ), performed in front of an audience of three individuals, which was preceded by an anticipation phase $(5 \mathrm{~min})$ in which participants prepared the speech. During the speech, participants took on the role of a jobapplicant (job-definition is predefined, based on what is challenging and relevant for the participant). In case participants reported being unable to proceed with the free speech they received a modified version of the TSST with up to three measures helping participants to fulfill the task, without dropping out. The measures were in fixed order, and the next step was applied only if necessary: (1) giving verbal encouragements during the free speech; (2) structured interview in stead of free speech, involving direct questions about job application; (3) preterm cancellation of free speech, and immediate continuation with the mental arithmetic task.

Table 1

Demographic variables and group characteristics.

\begin{tabular}{|c|c|c|c|c|c|c|}
\hline Variable & $\mathrm{SAD}+\mathrm{CA}(n=9)$ & $\mathrm{SAD}-\mathrm{CA}(n=9)$ & PTSD $(n=16)$ & $\mathrm{HC}(n=16)$ & $F$-value & $p$-value \\
\hline Gender (M/F) & $4 \mathrm{M} / 5 \mathrm{~F}$ & $4 \mathrm{M} / 5 \mathrm{~F}$ & $4 \mathrm{M} / 12 \mathrm{~F}$ & $5 \mathrm{M} / 11 \mathrm{~F}$ & $0.98\left(\chi^{2}\right)$ & 0.61 \\
\hline Age & $32.9(9.5)$ & $27.8(6.3)$ & $35.1(11.3)$ & $39.3(17.6)$ & 1.61 & 0.20 \\
\hline Axis-I comorbidity ${ }^{a}$ & 6 & 5 & 14 & 0 & $19.38\left(\chi^{2}\right)$ & 0.000 \\
\hline GAD & 1 & 1 & 3 & 0 & & \\
\hline Panic disorder & 0 & 0 & 4 & 0 & & \\
\hline Obsessive comp. dis. & 0 & 1 & 1 & 0 & & \\
\hline MDD & 4 & 3 & 5 & 0 & & \\
\hline Dysthymic disorder & 1 & 0 & 1 & 0 & & \\
\hline Medication ${ }^{\mathrm{b}}$ & $3 N / 6 Y$ & $4 N / 5 Y$ & $3 N / 13 Y$ & $11 \mathrm{~N} / 5 \mathrm{Y}$ & $8.38\left(\chi^{2}\right)$ & 0.04 \\
\hline $\mathrm{AD}$ & 3 & 3 & 2 & 0 & & \\
\hline Sedatives $^{c}$ & 2 & 2 & 3 & 0 & & \\
\hline Other ${ }^{\mathrm{d}}$ & 1 & 0 & 3 & 2 & & \\
\hline Oral contraceptives & 2 & 2 & 7 & 4 & & \\
\hline Social anxiety (SPAI) & 166.8 (20.6)ad & $152.0(29.2) b$ & $137.5(32.3) \mathrm{cd}$ & 92.3 (34.3)abc & 14.11 & 0.000 \\
\hline Depression (BDI) & $22.4(10.5) \mathrm{a}$ & $12.6(15.1) b$ & $17.1(13.4) c$ & 3.1 (2.1)abc & 7.45 & 0.000 \\
\hline Childhood abuse (TEC) & $4.3(1.9) \mathrm{a}$ & $1.8(1.3) \mathrm{b}^{\mathrm{e}}$ & $8.6(6.2) \mathrm{abc}$ & $2.3(2.1) \mathrm{c}^{\mathrm{e}}$ & 9.22 & 0.000 \\
\hline Emotional & $3.9(n=8)$ & $0.9(n=3)$ & $4.9(n=12)$ & $0.1(n=1)$ & 8.74 & 0.000 \\
\hline Physical & $0.8(n=3)$ & $0.0(n=0)$ & $2.2(n=8)$ & $0.1(n=1)$ & 6.12 & 0.001 \\
\hline Sexual & $0.7(n=2)$ & $0.0(n=0)$ & $4.6(n=12)$ & $0.1(n=1)$ & 9.89 & 0.000 \\
\hline \multicolumn{7}{|l|}{ Age } \\
\hline Emotional & 7.6 years $(1-15)$ & n.a. & 6.5 years $(1-14)$ & n.a. & & \\
\hline Physical & 5.5 years $(1-12)$ & n.a. & 5.1 years $(1-12)$ & n.a. & & \\
\hline Sexual & 7.0 years $(4-10)$ & n.a. & 7.1 years $(1-11)$ & n.a. & & \\
\hline \multicolumn{7}{|l|}{ Duration } \\
\hline Emotional & 10 years $(2-18)$ & n.a. & 13.4 years $(1-29)$ & n.a. & & \\
\hline Physical & 8.5 years $(6-12)$ & n.a. & 11.0 years $(2-24)$ & n.a. & & \\
\hline Sexual & 3.0 years $(3)$ & n.a. & 6.6 years $(1-16)$ & n.a. & & \\
\hline \multicolumn{7}{|l|}{ Impact } \\
\hline Emotional & $3.9(3-5)$ & n.a. & $3.8(2-5)$ & n.a. & & \\
\hline Physical & $2.5(2-3)$ & n.a. & $3.8(2-5)$ & n.a. & & \\
\hline Sexual & $2.5(2-3)$ & n.a. & $4.3(2-5)$ & n.a. & & \\
\hline
\end{tabular}

$n$ : number of participants.

Data from questionnaires are presented in mean score and SD.

Cells with similar letters differ significantly from each other $(p<0.05)$.

a Assessed using the SCID.

b Total numbers do not correspond with the sum of the four subtypes because of overlap (patients may use more than one type of medication).

c Participants refrained from taking the medication min. $24 \mathrm{~h}$ before the experiment.

${ }^{d}$ Including medication for respiratory tracts and blood pressure control.

e In the case of SAD - CA and HC, this only refers to events after 16 years. 


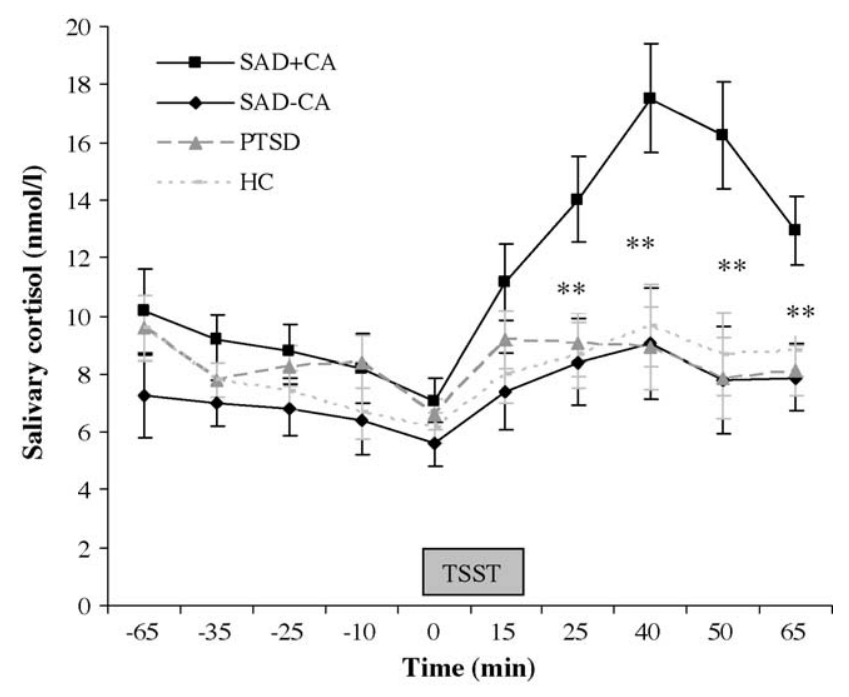

Fig. 1. Cortisol responses before, during and after stress exposure using the TSST. Patients with SAD and a history of childhood abuse (SAD + CA) have significantly larger cortisol responses to the TSST than SAD patients without a history of childhood abuse (SAD - CA), and control group patients with PTSD and healthy subjects. ${ }^{* *} p<0.01$.

\subsubsection{Cortisol, blood pressure, and subjective anxiety}

Salivary cortisol, blood pressure, and subjective anxiety measures were obtained at 10 assessment points over a 130 -min period, at $-65,-35,-25,-10,0,+15,+25$, $+40,+50$ and +65 min with reference to the start of the stressor (see Figs. 1 and 2 ). All assessments were performed between 1 PM and 4 PM. To assess free cortisol levels, saliva samples were obtained using Salivette collection devices (Sarstedt, Rommelsdorf, Germany). The samples were stored at $-20^{\circ} \mathrm{C}$ before assaying. Biochemical analysis of free cortisol in saliva was performed using a competitive electrochemiluminescence immunoassay (ECLIA, Elecsys 2010, Roche Diagnostics), as described elsewhere (Van Aken et al., 2003).

Blood pressure was measured from the non-dominant arm using an automatic blood pressure monitor (Omron R5-I) that could be initiated manually.

Subjective anxiety was measured using a visual analogue scale (ranging from 0 to 10) at each assessment point.

\subsubsection{Questionnaires}

Traumatic Experiences Checklist (TEC, Nijenhuis et al., 2002).

The TEC is a reliable and valid self-report inventory that assesses emotional abuse and neglect, physical abuse, sexual harassment, and sexual abuse, as well as general traumatic events, including loss of significant others, life threat by disease, parental divorce, and psychopathology of parents (i.e., alcohol or drug abuse). The TEC version that was used in the present study contains 26 items, with the total

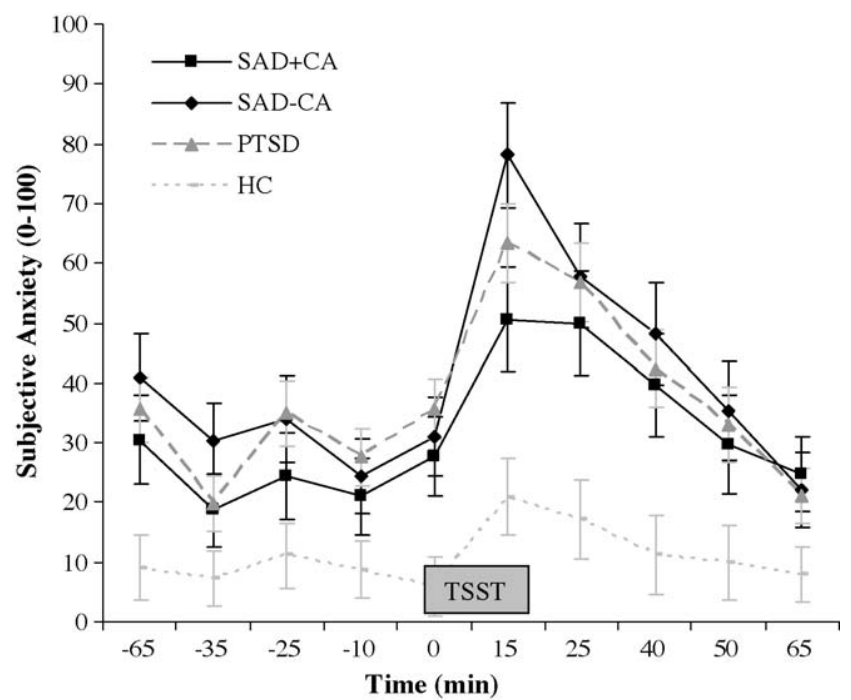

Fig. 2. Measures of subjective anxiety before, during and after stress exposure using the TSST. score ranging from 0 to 26 . Besides the total score, there are scores for the presence of emotional abuse (emotional neglect and emotional abuse in various settings, six items), physical abuse (physical abuse in various settings, intentional threat to life, and intense pain, five items), and sexual abuse (sexual harassment and sexual abuse in various settings, six items). For each item it was assessed whether the event happened yes or no, at which age the event first took place, at which age the event ended, and the impact of the event on a scale from 1 (not at all) to 5 (very much). All items are preceded by the phrase: "Did this happen to you?" An example of emotional abuse is: "Emotional abuse (e.g., being belittled, teased, called names, threatened verbally, or unjustly punished) by your parents, brothers or sisters".

Cronbach's $\alpha$ for the TEC total score is 0.86 . Cronbach's $\alpha$ for emotional abuse is 0.78 , for sexual abuse 0.65 , and for physical abuse 0.77 . Test-retest reliability of the TEC total score is $r=0.91$. The test-retest for the specific types of abuse: emotional abuse, $r=0.80$; physical abuse, $r=0.86$; sexual abuse, $r=0.88$ (all $p<0.0001$ ). Concurrent validity as measured by the correlation between the TEC and the Stressful Life Events Screening Questionnaire (SLESQ) total score (Goodman et al., 1998) is strong, $r=0.77, p<0.0001$ ).

To measure social anxiety, the social anxiety subscale of the Social Phobia and Anxiety Inventory (SPAI: Turner et al., 1989; Bögels and Reith, 1999) was used and depression severity was measured with the Beck Depression Inventory (BDI-II: Beck et al., 1961; van der Does, 2002).

\subsection{Procedure}

On the test day, participants arrived at the laboratory at 1.00 PM. After the first series of physiological and subjective assessments, subjects were adjusted to the experimental environment using a relaxing movie, followed by a battery of cognitive tests, of which the results are reported elsewhere (Roelofs et al., 2009). After $65 \mathrm{~min}$, the TSST was administered. Immediately after the TSST, the experimenter came back and administered the cognitive tests again in the presence of the audience (until $+25 \mathrm{~min}$ with reference to onset TSST). Subsequently, the audience left the room and returned for a debriefing after the last physiological assessment had taken place. One week after the experiment patients were contacted for a second debriefing (for more details, see Roelofs et al., 2009).

\subsection{Statistical analyses}

To compare the four groups on cortisol reactivity to the TSST, analyses of variance (ANOVA) for repeated measures were conducted with Group (SAD + CA vs SAD - CA vs PTSD vs HC) as between-subjects factor and Time (10 assessment points) as within-subjects factor, which was followed by univariate ANOVAs to clarify the significant effects. To control for the use of medication, gender differences, and modifications in TSST administration (see Roelofs et al., 2009), these factors were added as covariates in additional analyses. To investigate the specificity of the effects on cortisol reactivity, similar repeated measures ANOVAs were conducted for systolic and diastolic blood pressure and subjective anxiety. All statistical analyses described employed a two-tailed $\alpha$ of 0.05 , and effect sizes of significant results are reported to be using the Partial Eta Squared $\left(\eta^{2}\right)$. When sphericity could not be assumed, within-subject effects were corrected using the Greenhouse-Geisser procedure. Analyses were performed using SPSS 16.0.

\section{Results}

\subsection{Cortisol reactivity}

In the repeated measures ANOVA a main effect of Time was found, due to a significant increase in cortisol levels after the TSST $\left(F(9,414)=10.98, p<0.0001, \eta^{2}=0.19\right)$. Also a main effect of Group was found $\left(F(3,46)=4.03, p<0.05, \eta^{2}=0.21\right)$, which was specified by a significant Group $\times$ Time interaction $(F(27,414)=2.62$, $p<0.05, \eta^{2}=0.15$ ) (see Fig. 1). Follow-up univariate ANOVA analyses at the separate time points showed that this was due to the fact that SAD + CA patients had higher cortisol levels compared to the other three groups after stress induction (at $+25 \mathrm{~min}$ $(F(3,49)=3.51, \quad p<0.05) ; \quad+40 \min (F(3,49)=5.35, \quad p<0.005)$; $+50 \min (F(3,49)=5.21, p<0.005)$, and $+65 \min (F(3,49)=4.46$, $p<0.01$ )), but not at baseline (from -65 to $+0 \mathrm{~min}$, all $p s>0.2$ ), nor immediately after the TSST (at +15 min: $p=0.17$ ). At all time points from +25 to +60 min the SAD + CA group had significantly higher cortisol levels than the SAD - CA, PTSD and HC group (all $p s<0.01$ ), whereas the SAD - CA, PTSD and HC did not differ (all $p s>0.5$ ).

When controlling for Gender, Medication and TSST-modifications as covariates, the main effect of Group $(F(3,43)=5.27$, $\left.p<0.005, \quad \eta^{2}=0.27\right)$ and the Group $\times$ Time interaction 
$\left(F(27,387)=2.37, p<0.05, \eta^{2}=0.14\right)$ remained significant. The TSST-modification was a significant covariate which had a main effect $\left(F(1,43)=7.38, p<0.01, \eta^{2}=0.15\right)$, indicating that participants with modified (i.e., milder) versions of the TSST had lower cortisol levels (see also Roelofs et al., 2009). Gender did not show a main effect, but interacted with time $(F(9,387)=3.36, p<0.05$, $\eta^{2}=0.07$ ), due to larger cortisol increases after the TSST in men than in women. Use of medication was not a significant covariate $(F(1,43)=1.85$, n.s. $)$.

Finally, to control for depression rates, the individual BDI-II total-scores were entered as an additional covariate into the model. This did not affect the findings either: main effect of Group $\left(F(3,42)=5.79, \quad p<0.005, \quad \eta^{2}=0.29\right)$ and Group $\times$ Time effect $\left(F(27,378)=2.31, p<0.05, \eta^{2}=0.14\right)$. Moreover, depression was not a significant covariate $(F(1,42)=1.89$, n.s. $)$, nor did depression interact with Time $(F(9,387)=0.43$, n.s. $)$. The same was true when controlling for social anxiety severity as measured with the SPAI (main effect of Group $\left(F(3,42)=3.77, p<0.05, \eta^{2}=0.21\right.$ ) and Group $\times$ Time effect $\left.\left(F(27,378)=2.41, p<0.05, \eta^{2}=0.15\right)\right)$. Social anxiety was not a significant covariate $(F(1,42)=0.05$, n.s. $)$, nor did it interact with Time $(F(9,387)=1.72, n . s$.$) .$

\section{Blood pressure}

The repeated measures ANOVA on blood pressure showed a significant increase in both systolic blood pressure (main effect of Time: $\left.F(9,405)=11.63, p<0.0001, \eta^{2}=0.21\right)$ and diastolic blood pressure $\left(F(9,405)=10.56, p<0.0001, \eta^{2}=0.19\right)$ in response to the TSST, but no interaction with group (systolic blood pressure: $F(27,405)=1.24$, n.s.; diastolic blood pressure: $F(27,405)=1.31$, n.s.) nor a main effect of group (systolic blood pressure: $F(3,45)=0.50, n . s$; diastolic blood pressure: $F(3,45)=1.15$, n.s. $)$.

\section{Subjective anxiety}

The repeated measures ANOVA on subjective anxiety revealed a significant increase in anxiety after the TSST (main effect of Time: $\left.F(9,414)=26.80, p<0.0001, \eta^{2}=0.37\right)$. Independent of time, higher anxiety levels were reported by all three patient groups compared to controls (main effect of Group: $F(3,46)=8.26$, $p<0.0001, \eta^{2}=0.35$ ). A significant Group $\times$ Time interaction also emerged $\left(F(27,414)=2.10, p<0.05, \eta^{2}=0.12\right.$, see Fig. 2$)$. Followup univariate ANOVA analyses at the separate time points showed significant group differences at all time points (all $p s<0.05$ ) except at $+65 \mathrm{~min}(p=0.10)$. At the first time point $(-65 \mathrm{~min})$ the SAD + CA, SAD - CA and the PTSD group had significantly higher anxiety ratings compared to the HC group $(p<0.05)$, whereas the patient groups did not differ. At time point $-35,-25$ and $-10 \mathrm{~min}$, PTSD patients and SAD - CA had significantly higher anxiety ratings compared to the $\mathrm{HC}$ group (all $p s<0.05$ ), whereas the $\mathrm{SAD}+\mathrm{CA}$ did not significantly differ from the HC group. Immediately before the TSST until +50 min after the TSST, all three patient groups reported higher anxiety ratings than the HC group (all $p<0.05$ ). In addition, immediately after the TSST (at $+15 \mathrm{~min}), \mathrm{SAD}+\mathrm{CA}$ had lower anxiety ratings compared to the SAD - CA group $(p<0.05)$.

\section{Discussion}

We found that a history of CA was associated with greatly enhanced cortisol reactivity to a psychosocial stress task in patients with SAD compared to patients with SAD who did not report childhood abuse, and compared to patients with PTSD related to CA and healthy controls without a history of CA. No differences in baseline cortisol levels were found. Interestingly, the increased cortisol response in the SAD +CA group was not associated with enhanced blood pressure, nor with enhanced subjective anxiety. In contrast, anxiety ratings in the SAD + CA group were even lower immediately after stress induction than the SAD - CA group. This is consistent with previous studies on the impact of early adverse experiences on HPA-axis reactivity, showing that changes in HPA-axis reactivity occur independent of other neurobiological changes (Elzinga et al., 2008) and independent of the emotional appraisal of the stress context (Heim et al., 2000; Elzinga et al., 2008)

To the best of our knowledge, this is the first study showing that CA is associated with increased cortisol reactivity in SAD. These findings are remarkably consistent with studies in MDD, where HPA-axis hyperreactivity was also found in individuals with a history of CA (Heim et al., 2000, 2002). Moreover, the increased cortisol reactivity was not driven by the more severe depression scores in this group, since the effects of abuse remained unchanged and significant when controlling for depression severity. The enhanced cortisol reactivity in the SAD + CA group was neither explained by social anxiety severity. It should be noted that the assessment of childhood abuse was based on subjective reports and therefore we cannot exclude the possibility that those SAD patients with high cortisol reactivity might recollect more childhood abuse (rather than differ in the number or experience of childhood abuse). However, thinking along these lines one would expect inflated subjective reports on other measures as well (e.g., subjective anxiety ratings), but this was not the case. Moreover, previous studies in healthy subjects found exactly the opposite pattern that increased cortisol levels were associated with low reports of abuse (see Elzinga et al., 2008; Carpenter et al., 2007), suggesting that there is at least not a general pattern that enhanced cortisol reactivity is associated with an inflated recollection of traumatic events.

Taken together with the studies in patients with MDD, these studies support the notion derived from animal research that chronic stress during childhood is associated with a persistent sensitization of the HPA-axis to stress (Heim and Nemeroff, 2001; Kaufman et al., 2000; Sanchez, 2006). Moreover, the enhanced cortisol reactivity in SAD patients reported earlier (see Roelofs et al., 2009) was completely driven by the SAD patients with a history of CA, as the SAD patients without CA did not differ from healthy controls, despite very high anxiety levels during the TSST. This suggests that the impact of CA on HPA-axis reactivity may partly explain the mixed findings in previous SAD studies on cortisol reactivity (see Condren et al., 2002; Furlan et al., 2001; Levin et al., 1993; Martel et al., 1999).

Interestingly, PTSD patients did not show enhanced cortisol reactivity to the TSST. At first sight, this seems to suggest that CA differentially affected the HPA-axis in PTSD vs SAD. It should be noted, however, that several factors might have played a role in the differences in cortisol levels between the SAD + CA and PTSD patients. First, the types and severity of abuse reported by SAD and PTSD patients were different, with PTSD patients reporting more frequent and more severe physical and sexual abuse. In SAD, emotional abuse was most prevalent and most severe, in line with studies showing that emotional abuse and neglect particularly predispose individuals for the development of SAD (Gibb et al., 2007). Moreover, a relatively large number of PTSD patients $(n=7)$ took oral contraceptives (in contrast to two participants in the $\mathrm{SAD}+\mathrm{CA}$ and two participants in the SAD - CA group), which might have blunted cortisol reactivity in the PTSD group (see Kirschbaum et al., 1999; Kudielka and Kirschbaum, 2005). Finally, also the type of stressor might have played an important role. A core feature of SAD is a fear of social situations in which a person may be embarrassed or humiliated, which bears close resemblance to the TSST. Thus, whereas the TSST is a specific symptom provoking context for SAD patients, this is not the case for PTSD 
patients. This may explain the absence of increased cortisol reactivity in PTSD patients in the present study, whereas in a previous study in which PTSD patients were exposed to personalized trauma scripts, PTSD patients did show elevated cortisol levels (see Elzinga et al., 2003). In sum, a number of factors, including type of trauma, type of stressor (i.e., trauma-related or not), use of medication including oral contraceptives, but also gender distribution, may all effect HPA-axis reactivity, making it difficult to draw final conclusions on the status of HPA-axis reactivity in PTSD (see also De Kloet et al., 2006).

In combination with recent findings that emotional abuse and neglect is an important etiological factor in SAD (Gibb et al., 2007), the present results suggest that one of the pathways from abuse to the development of SAD (and MDD) might be associated with enhanced cortisol reactivity to stress. We acknowledge that the results are based on a small number of patients, and therefore inferences should be made with caution. However, if replicated in larger samples, these findings lead to the intriguing possibility that childhood abuse might be associated with resilience, as indexed by reduced cortisol reactivity (see Elzinga et al., 2008; Carpenter et al., 2007) in those who emerge from the abuse without a disorder, but vulnerability, as indexed by enhanced cortisol reactivity, in those who emerge from the abuse with a psychiatric disorder, such as SAD, MDD (Heim et al., 2001), and perhaps PTSD (Elzinga et al., 2003; Bremner et al., 2003). In the context of prevention, it is important to identify factors that might predict who will emerge as resilient and will be at risk to develop an affective disorder as a result of early abuse. One step forward in predicting risk would be to combine data on HPA-axis sensitization with genetics. It has been shown that genetic factors (e.g., the serotonin transporter gene 5-HTTLPR, and FKBP5 which is associated with GR responsiveness) may in part determine who is at risk to develop psychopathology after being exposed to childhood abuse (see Caspi et al., 2003; Kendler et al., 2005; Binder et al., 2008). Interestingly, some of these same genes also appear to be associated with alterations in HPA-axis reactivity after stress exposure (Binder et al., 2008; McCormack et al., 2009; see also Ouellet-Morin et al., 2008). When investigated in combination with other risk and protective factors (i.e., social support, and exposure to adult negative and positive life events), gene $\times$ environment studies on HPA-axis reactivity might help to identify the more vulnerable vs resilient individuals in the face of early life stress.

Finally, if enhanced cortisol reactivity is indeed characteristic of SAD patients with a history of abuse, this may also potentially open interesting new venues for exploring the reversibility of this stress sensitization. On the one hand, it will be interesting to investigate the efficacy of pharmacological interventions directly aimed at reducing cortisol levels (i.e., MR or GR antagonists). On the other hand, a study in chronically depressed patients has shown that among depressed patients with a history of early childhood trauma psychotherapy was superior in reducing depressive symptoms compared to antidepressant monotherapy. Along these lines, one would expect that psychotherapy is also an essential element in the treatment of SAD patients with a history of early abuse. Taken together, this study should be considered as a first step in understanding the impact of CA on HPA-axis sensitization in SAD, which, if replicated in larger samples, may have important implications for the prevention and treatment of SAD.

\section{Conflict of interest}

B. Elzinga, Ph. Spinhoven, E. Berretty, P. de Jong, and K. Roelofs reported no biomedical financial interests or potential conflicts of interest.

\section{Acknowledgements}

This study was supported by VIDI Grants (\#016-085-353) and (\#452-07-008) from the Netherlands Organization for Scientific Research (NWO) awarded to Dr. B. Elzinga and Dr. K. Roelofs, respectively. The authors thank Mea-Ann Haime, Gisella Lijde, Willemieke Maasland, Jaques Meulman, Saskia van Bodegom, Jocelyn van de Moolen, Sarah van der Zeeuw, Mariette van het Schip, Lennard van Ree, and Robert van Roon for their assistance during data collection; Jolanda Verhagen and Hans van Pelt (Department of Clinical Chemistry, Leiden University Medical Centre: LUMC) for conducting the biochemical analyses.

\section{References}

Beck, A.T., Ward, C.H., Mendelsohn, M., Mock, J., Erbaugh, J., 1961. An inventory for measuring depression. Archives of General Psychiatry 4, 561-571.

Binder, E.B., Bradley, R.G., Liu, W., Epstein, M.P., Deveau, T.C., Mercer, K.B., Tang, Y., Gillespie, C.F., Heim, C.M., Nemeroff, C.B., Schwartz, A.C., Cubbels, J.F., Ressler, K.J., 2008. Association of FKBP5 polymorphisms and childhood abuse with risk of Posttraumatic Stress Disorders Symptoms in adults. Journal of the American Medical Association 299, 1291-1305.

Bögels, S.M., Reith, W., 1999. Validity of two questionnaires to assess social fears: the Dutch Social Phobia and Anxiety Inventory and the Blushing, Trembling and Sweating Questionnaire. Journal of Psychopathology and Behavior Assessment 21, 51-66.

Bremner, J.D., Vythilingam, M., Vermetten, E., Adil, J., Khan, S., Nazeer, A., Afzal, N., Elzinga, B., Schmahl, C., McGlashan, T., Anderson, G., Heninger, G., Southwick, S.M., Charney, D.S., 2003. Cortisol response to a cognitive stress challenge in posttraumatic stress disorder (PTSD) related to childhood abuse. Psychoneuroendocrinology 28, 733-750.

Carpenter, L.L., Carvalho, J.P., Tyrka, A.R., Wier, L.M., Mello, A.F., Mello, M.F., Anderson, G.M., Wilkinson, C.W., Price, L.H., 2007. Decreased adrenocorticotropic hormone and cortisol responses to stress in healthy adults reporting significant childhood maltreatment. Biological Psychiatry 15, 1080-1087.

Caspi, A., Sugden, K., Moffitt, T.E., Taylor, A., Craig, I.W., Harrington, H., et al., 2003. Influence of life stress on depression: moderation by a polymorphism in the 5HTT gene. Science 301, 386-389.

Condren, R.M., O'Neill, A., Ryan, M.C.M., Barrett, P., Thakore, J.H., 2002. HPA axis response to a psychological stressor in generalized social phobia. Psychoneuroendocrinology 27, 693-704.

De Kloet, C.S., Vermetten, E., Geuze, E., Kavelaars, A., Heijnen, C.J., Westenberg, H.G., 2006. Assessment of HPA-axis function in posttraumatic stress disorder: pharmacological and non-pharmacological challenge tests, a review. Journal of Psychiatry Research 40, 550-567.

Elzinga, B.M., Schmahl, C.S., Vermetten, E., van Dyck, R., Bremner, J.D., 2003. Higher cortisol levels following exposure to traumatic reminders in abuse related PTSD. Neuropsychopharmacology 28, 1656-1665.

Elzinga, B.M., Roelofs, K., Tollenaar, M.S., Bakvis, P., van Pelt, J., Spinhoven, Ph., 2008. Diminished cortisol responses to psychosocial stress associated with lifetime adverse events. Psychoneuroendocrinology 33, 227-237.

First, M.B., Spitzer, R.L., Gibbon, M., Williams, J.B.W., 1996. Structured Clinical Interview for DSM-IV Axis I Disorders, Version 2.0. Biometrics Research, New York.

Furlan, P.M., DeMartinis, N., Schweizer, E., Rickels, K., Lucki, I., 2001. Abnormal salivary cortisol levels in social phobic patients in response to acute psychological but not physical stress. Biological Psychiatry 50, 254-259.

Gibb, B.E., Chelminski, I., Zimmerman, M., 2007. Childhood emotional, physical, and sexual abuse, and diagnoses of depressive and anxiety disorders in adult psychiatric outpatients. Depression and Anxiety 24, 256-263.

Goodman, L.A., Corcoran, C., Turner, K., Yuan, N., Green, B., 1998. Assessing traumatic event exposure: general issues and preliminary findings for the Stressful Life Events Screening Questionnaire. Journal of Traumatic Stress 11, 521-542.

Heim, C., Nemeroff, C.B., 2001. The role of childhood trauma in the neurobiology of mood and anxiety disorders: preclinical and clinical studies. Biological Psychiatry 49, 1023-1039.

Heim, C., Newport, D.J., Bonsall, R., Miller, A.H., Nemeroff, C.B., 2001. Altered pituitary-adrenal axis responses to provocative challenge tests in adult survivors of childhood abuse. Biological Psychiatry 158, 575-581.

Heim, C., Newport, D.J., Heit, S., Graham, Y.P., Wilcox, M., Bonsall, R., et al., 2000. Pituitary-adrenal and autonomic responses to stress in women after sexual and physical abuse in childhood. Journal of the American Medical Association 284, 592-597.

Heim, C., Newport, D.J., Wagner, D., Wilcox, M.M., Miller, A.H., Nemeroff, C.B., 2002. The role of early adverse experience and adulthood stress in the prediction of neuroendocrine stress reactivity in women: a multiple regression analysis. Depression and Anxiety 153, 117-125.

Kaufman, J., Plotsky, P.M., Nemeroff, C.B., Charney, D., 2000. Effects of early adverse experiences on brain structure and function: clinical implications. Biological Psychiatry 48, 778-790. 
Kendler, K.S., Kuhn, J.W., Vittum, J., et al., 2005. The interaction of stressful life events and a serotonin transporter polymorphism in the prediction of episodes of major depression. Archives of General Psychiatry 62, 529-535.

Kirschbaum, C., Kudielka, B.M., Gaab, J., Schommer, N.C., Helhammer, D.H., 1999 Impact of gender, menstrual cycle phase, and oral contraceptives on the activity of the hypothalamus pituitary-adrenal axis. Psychosomatic Medicine 612, 154162.

Kudielka, B.M., Kirschbaum, C., 2005. Sex differences in HPA axis responses to stress: a review. Biological Psychology 69, 113-132.

Levin, A.P., Saoud, J.B., Strauman, T., Gorman, J.M., Fyer, A.J., Crawford, R., Liebowitz, M.R., 1993. Responses of "generalized" and "discrete" social phobics during public speaking. Journal of Anxiety Disorders 7, 207-221.

Mannuzza, S., Schneier, F.R., Chapman, T.F., Liebowitz, M.R., Klein, D.F., Fyer, A.J. 1995. Generalized social phobia. Reliability and validity. Archives of Genera Psychiatry 52, 230-237.

Martel, F.L., Hayward, C., Lyons, D.M., Sanborn, K., Varady, S., Schatzberg, A.F., 1999 Salivary cortisol levels in socially phobic adolescent girls. Depression and Anxiety 10, 25-27.

McCormack, K., Newman, T.K., Higley, J.D., Maestripieri, D., Sanchez, D., 2009. Serotonin transporter gene variation, infant abuse, and responsiveness to stress, in rhesus macaque mothers and infants. Hormones and Behavior 55, 538-547.

McGowan, P.O., Sasaki, A., D’Alessio, A.C., Dymov, S., Labonté, B., Szyf, M., Turecki, G., Meaney, M.J., 2009. Epigenetic regulation of the glucocorticoid receptor in human brain associates with childhood abuse. Nature Neuroscience 12, 342-348.

Nijenhuis, E.R.S., Van der Hart, O., Kruger, K., 2002. The psychometric characteristics of the Traumatic Experiences Questionnaire (TEC): first findings among psychiatric outpatients. Clinical Psychology and Psychotherapy 9, 200-210.
Ouellet-Morin, I., Boivin, M., Dionne, G., Lupien, S.J., Arsenault, L., Barr, R.G., Perusse, D. Tremblay, R.G., 2008. Variations in heritability in cortisol reactivity to stress as a function of early familial adversity among 19-month-old twins. Archives of General Psychiatry 65, 211-218.

Roelofs, K., van Peer, J., Berretty, E., de Jong, P., Spinhoven, Ph., Elzinga, B.M., 2009. HPA-axis hyperresponsiveness is associated with increased social avoidance behavior in social phobia. Biological Psychiatry 65, 336-343.

Sanchez, M.M., 2006. The impact of early adverse care on HPA axis development: nonhuman primate models. Hormones and Behavior 50, 623-631.

Stein, M.B., Stein, D.J., 2008. Social anxiety disorder. Lancet 29 (371), 11151125

Turner, S.M., Beidel, D.C., Dancu, C.V., Stanley, M.A., 1989. An empirically derived inventory to measure social fears and anxiety: the Social Phobia and Anxiety Inventory. Psychological Assessment 1, 35-40.

Van Aken, M.O., Romijn, J.A., Miltenburg, J.A., Lentjes, E.G.W.M., 2003. Automated measurement of cortisol. Clinical Chemistry 49, 1408-1409.

van der Does, A.J.W., 2002. BDI-II-NL. Handleiding. De Nederlandse versie van de Beck Depression Inventory, 2nd edition (Dutch Translation of the Beck Depression Inventory, 2nd edition) Lisse Harcourt Test Publishers.

Weaver, I.C.G., Cervoni, N., Champagne, F.C., D’Alessio, A.C., Sharma, S., Seckl, J.R. Dymov, S., Szyf, M., Meaney, M.J., 2004. Epigenetic programming by maternal behavior. Nature Neuroscience 7, 847-854.

Weaver, I.C.G., D’Alessio, A.C., Brown, S.E., Hellstrom, I.C., Dymov, S., Sharma, S. Szyf, M., Meaney, M.J., 2007. The transcription factor nerve growth factorinducible protein A mediates epigenetic programming: altering epigenetic marks by immediate-early genes. Journal of Neurosciences 27, 17561768. 